\title{
TRANSPORT OF DEXTRAN SULFATES TO RAT LIVERS
}

\author{
Kyoichi KAGAWA and Setsuo TOMIZAWA \\ Department of Pharmacology, School of Pharmaceutical Sciences, \\ Kitasato University, Minato-ku, Tokyo 108, Japan
}

Accepted May 2, 1979

\begin{abstract}
Liver subcellular distributions of three different dextran sulfates (DSs) with average molecular weight (AMW) of 3000,20,000 and 200,000, and sulfur content of $18 \%$, anticoagulants and antilipemic agents, were examined in rats after intravenous administration of $50 \mathrm{mg} / \mathrm{kg}$. About $20 \%$ of the injected radioactivity was taken up by liver $15 \mathrm{~min}-3 \mathrm{hr}$ after ${ }^{35} \mathrm{~S}$-DS administration, but the uptake of ${ }^{35} \mathrm{~S}-\mathrm{DS}$ with AMW of 200,000 was slower tha.، that of the other DSs. About half of the radioactivity distributed in livers was fol. $\mathrm{d}$ in the cytosol fraction. The cytosol fraction/liver ratio of the radioactivity gradually decreased with the increase in the nuclear fraction/liver ratio. The specific radioactivity of the lysosomal fraction was 5-20 times as large as that of the other fractions. Unchanged forms of ${ }^{35}$ S-DSs with AMW of 3000 and 20,000 were found in the lysosomal and the cytosol fractions. Administration of DSs with AMW of 20,000 and 200,000 significantly enhanced the $\mathrm{Na}^{+}-\mathrm{K}^{+}$-dependent ATPase activity of lysosomal fraction which has been considered to be an index of endocytosis. These findings suggest that DSs are probably transferred into liver cells by transmembrane and endocytotic transports.
\end{abstract}

Heparin given i.v. in high doses is distributed into the extracellular spaces (1). Kaplan and Meyer (2) reported that chondroitin sulfates were excreted mainly into the urine. Thus, acid polysaccharides may rapidly distribute to extracellular spaces and be excreted into the urine. The mechanism of the transport into cells has, however, not been elucidated.

In a previous report (3) we showed that, when a heparinoid having strong anticoagulant and antilipemic activities, ${ }^{35} \mathrm{~S}-\mathrm{DS}$ with average molecular weight of 200,000 and sulfur content of $18 \%$, was given intraduodenally, large amounts of the radioactivity were found in the bile, the concentration being twice that found in the blood. Therefore, it may be that DSs are eliminated from circulation by two routes, via kidneys and liver. When given intraduodenally, ${ }^{35} \mathrm{~S}-\mathrm{DS}$ or, at least, the radioactivity absorbed intestinally must pass through liver. Accordingly, it is possible that only the radioactivity of inorganic ${ }^{35} \mathrm{~S}$-sulfate ion is transferred to liver cells and excreted in bile. To determine whether or not DSs can indeed enter liver cells, we examined the subcellular distribution of DSs in rat liver after intravenous administration.

\section{MATERIALS AND METHODS}

Experimental animals: Female Donryu rats (Nihon Rat Co., Urawa), weighing about $200 \mathrm{~g}$, were used after an 18-hr fast.

Composition of DSs: The composition of DSs used in the experiments was as follows: DS-L, intrinsic viscosity (IV) 0.027 , average molecular weight (AMW) 3000, sulfur content 
(SC) $18.3 \%$; DS-M, IV 0.082, AMW 20,000, SC 18.1\%; DS-H, IV 0.198, AMW 200,000, SC $18.1 \%$. All the DSs were labeled with ${ }^{35} \mathrm{~S}$, and had a specific activity of about $1.5 \mu \mathrm{Ci} / \mathrm{mg}$.

Drug administration: Sodium salt of each ${ }^{35}$ S-DSs was dissolved in $0.9 \%$ saline in a concentration of $100 \mathrm{mg}(150 \mu \mathrm{Ci}) / \mathrm{ml}$, and the solutions were given into a femoral vein.

Subcellular fractionation: Rats were decapitated $15 \mathrm{~min}, 1,3$, and $24 \mathrm{hr}$ after administration of ${ }^{35} \mathrm{~S}$-DS $50 \mathrm{mg}(75 \mu \mathrm{Ci}) / \mathrm{kg}$. The livers were immediately perfused with cold $0.9 \%$ saline and subsequently with cold $0.25 \mathrm{M}$ sucrose by cannulation to the portal vein. The subcellular fractions of the livers were prepared by differential centrifugation according to the method of DeDuve et al. (4). A $10 \%(\mathrm{w} / \mathrm{v})$ homogenate in $0.25 \mathrm{M}$ sucrose was filtered once through nylin mesh, and pelleted at $2000 \mathrm{~g}$ for $10 \mathrm{~min}$. The pellet was washed with sucrose, and pelleted a second time. The resulting pellet constituted the nuclear fraction. The supernatant fractions from both washes were combined, and centrifuged at $8000 \mathrm{~g}$ for $10 \mathrm{~min}$ to produce the mitochondrial pellet. The pellet was washed with sucrose, and centrifuged. The supernatant fractions were centrifuged at $25,000 \mathrm{~g}$ for $20 \mathrm{~min}$ to produce the lysosomal pellet. The pellet was washed once with sucrose. The supernatant fractions were centrifuged at $105,000 \mathrm{~g}$ for $60 \mathrm{~min}$. The pellet was then washed once with sucrose, and centrifuged to produce the microsomal pellet. The remaining supernatant and the washing were combined, and regarded as the soluble fraction, namely the cytosol. Each of the pellets was suspended in distilled water.

The purity of each fraction was confirmed by the assay of marker enzymes: succinate dehydrogenase in mitochondria, acid p-nitrophenyl phosphatase in lysosomes, and glucose 6-phosphatase in microsomes. In this experiment, contamination by other fractions was determined to be less than $8 \%$.

Identification of ${ }^{35} \mathrm{~S}-\mathrm{DSS}$ and their radioactive metabolites: Each subcellular fraction was suspended in distilled water. To the aliquots was added $10 \%$ (final) trichloroacetic acid. The solution was centrifuged, and the pellet was washed with $5 \%$ trichloroacetic acid. The supernatant and the washing were combined, and treated with ether. The resulting aqueous phase was neutralized with $1 \mathrm{~N} \mathrm{NaOH}$. According to the method of Scott (5), $10 \%$ cetylpyridinium chloride $(\mathrm{CPC})$ was added to the solution, and the complex of CPC and DSs with AMW of 20,000 or above and SC of about $18 \%$ were pelleted. The complexes were dissolved by addition of $2 \mathrm{M} \mathrm{NaCl}$, and $80 \%$ (final) ethanol was subsequently added. The solution was centrifuged to produce the precipitates of DSs. They were washed twice with ethanol and ether. The final precipitates were dissolved in distilled water. The aliquots were subjected to paper electrophoresis: filter paper, Toyo No. 51A; Veronal buffer, $\mathrm{pH} 7.4 ; 0.5 \mathrm{~mA} / \mathrm{cm}$ for $60 \mathrm{~min}$.

After removal of CPC-DS complexes, the supernatant and the washings were combined, and $80 \%$ (final) ethanol containing $2 \% \mathrm{Na}_{2} \mathrm{SO}_{4}$ was added. The solution was centrifuged to produce precipitates consisting of the remaining radioactivity, namely inorganic ${ }^{35} \mathrm{~S}$-sulfate and ${ }^{35} \mathrm{~S}-\mathrm{DSs}$ with SC of $8 \%$ or below. These precipitates were washed twice with ethanol and ether, and the final preparations were dissolved in distilled water. The aliquots were paper chromatographed (6): filter paper, Toyo No. 51A; $70 \mathrm{mM}$ phosphate buffer (pH 6.4) 
in $25 \% \mathrm{n}$-propanol; $4{ }^{\circ} \mathrm{C}$ for $20 \mathrm{hr}$.

These filter papers were dissected in an adequate length, immersed in a vial containing a scintillator, and the radioactivity was counted with a Liquid Scintillation Spectrophotometer, Aloka LSC-651. The radioactivity in the paper strips of $\mathrm{Rf} 0.50-0.20$ was extracted with distilled water, and an aliquot of the extract was subjected to paper electrophoresis.

Assay and determination: $\mathrm{Na}^{+}-\mathrm{K}^{+}$-dependent ATPase was assayed by the method of Quigley and Gotterer (7). The incubation system consisted of $120 \mathrm{mM} \mathrm{NaCl}, 20 \mathrm{mM} \mathrm{KCl}$, $7.5 \mathrm{mM} \mathrm{MgCl}_{2}, 30 \mathrm{mM}$ tris-HCl buffer (pH 7.4), $5 \mathrm{mM}$ ATP-tris and $0.2 \mathrm{mg}$ of the lysosomal protein at $37^{\circ} \mathrm{C}$ for $10 \mathrm{~min}$, in the presence or absence of $0.5 \mathrm{mM}$ ouabain. Protein concentrations were measured by the method of Lowry et al. (8). The radioactivity was counted using liquid scintillation spectrophotometry.

\section{RESULTS}

The subcellular distribution of the radioactivity in liver after ${ }^{35} \mathrm{~S}-\mathrm{DS}$ administration is shown in Table 1. After administration of ${ }^{35} \mathrm{~S}-\mathrm{DS}-\mathrm{L}$ or ${ }^{35} \mathrm{~S}-\mathrm{DS}-\mathrm{M}$, the radioactivity was

TABLE 1. Subcellular distribution of the radioactivity of rat liver after administration of ${ }^{35} \mathrm{~S}$-DSs

\begin{tabular}{|c|c|c|c|c|c|c|c|}
\hline \multirow{3}{*}{ Treatment } & \multirow{3}{*}{$\begin{array}{l}\text { Subcellular } \\
\text { fraction }\end{array}$} & \multicolumn{6}{|c|}{ Time after administration } \\
\hline & & \multicolumn{2}{|c|}{$15 \mathrm{~min}$} & \multicolumn{2}{|c|}{$60 \mathrm{~min}$} & \multicolumn{2}{|c|}{$180 \mathrm{~min}$} \\
\hline & & $\%$ of dose & $\begin{array}{l}\mathrm{dpm} \times 10^{-3} \\
\mathrm{mg} \text { protein }\end{array}$ & $\%$ of dose & $\begin{array}{c}\mathrm{dpm} \times 10^{-3} / \\
\mathrm{mg} \text { protein }\end{array}$ & $\%$ of dose & $\begin{array}{l}\mathrm{dpm} \times 10^{-3} / \\
\mathrm{mg} \text { protein }\end{array}$ \\
\hline \multirow{6}{*}{ DS-L } & $\mathrm{NC}$ & $2.3 \pm 0.2$ & $2.9 \pm 0.9$ & $3.9 \pm 1.7$ & $4.8 \pm 1.1$ & $1.0 \pm 0.3$ & $1.3 \pm 0.1$ \\
\hline & MT & $2.3 \div 1.4$ & $1.7 \pm 0.3$ & $2.6 \pm 1.2$ & $2.0 \pm 0.4$ & $0.5 \pm 0.1$ & $0.4 \pm 0.1$ \\
\hline & LS & $2.7 \pm 0.5$ & $43.9 \pm 7.4$ & $2.1 \pm 0.6$ & $33.7 \pm 5.4$ & $0.6 \pm 0.1$ & $9.8 \pm 1.3$ \\
\hline & MS & $3.1 \pm 1.9$ & $2.9 \pm 0.7$ & $1.6 \pm 0.5$ & $1.4 \pm 0.1$ & $0.2 \pm 0.1$ & $0.2 \pm 0.1$ \\
\hline & $\mathrm{CS}$ & $10.4 \div 1.4$ & $6.3 \pm 2.0$ & $7.5 \pm 3.0$ & $4.6 \pm 0.8$ & $1.0 \pm 0.3$ & $0.6 \pm 0.1$ \\
\hline & Total & $20.8 \pm 4.9$ & $3.8 \pm 0.8$ & $17.7 \pm 3.2$ & $3.2 \pm 0.8$ & $3.3 \pm 1.3$ & $0.7 \pm 0.3$ \\
\hline \multirow{6}{*}{$\therefore M$} & NC & $3.2 \pm 0.3$ & $4.1 \pm 1.1$ & $3.6 \pm 0.5$ & $2.8 \pm 0.7$ & $2.0 \pm 0.5$ & $2.4 \pm 0.6$ \\
\hline & MT & $1.5 \pm 0.3$ & $1.1 \pm 0.3$ & $2.4 \pm 0.1$ & $1.8 \pm 0.2$ & $2.3 \pm 0.1$ & $1.8 \pm 0.2$ \\
\hline & LS & $2.1 \pm 0.3$ & $33.7 \pm 8.3$ & $2.1 \pm 0.3$ & $34.1 \pm 4.2$ & $2.0 \pm 0.1$ & $32.1 \pm 7.5$ \\
\hline & MS & $2.7 \pm 0.5$ & $2.4 \pm 0.6$ & $1.5 \pm 0.2$ & $1.4 \pm 0.3$ & $1.6 \pm 0.4$ & $1.5 \pm 0.3$ \\
\hline & $\mathrm{CS}$ & $11.6 \pm 1.4$ & $7.3 \pm 1.3$ & $7.7 \pm 0.9$ & $4.6 \pm 0.8$ & $7.9 \pm 0.9$ & $5.1 \pm 1.9$ \\
\hline & Total & $21.1 \pm 1.4$ & $4.3 \pm 1.0$ & $17.3 \pm 0.5$ & $3.4 \pm 0.7$ & $15.8 \pm 1.5$ & $3.1 \pm 0.8$ \\
\hline \multirow{6}{*}{ DS-H } & $\mathrm{NC}$ & $1.4 \div 0.5$ & $1.7 \pm 0.4$ & $2.9 \pm 1.1$ & $3.4 \pm 0.8$ & $3.4 \pm 0.9$ & $4.3 \pm 1.0$ \\
\hline & MT & $0.9-0.3$ & $0.7 \pm 0.2$ & $1.4 \pm 0.1$ & $1.1 \pm 0.3$ & $1.7 \pm 0.4$ & $1.3 \pm 0.1$ \\
\hline & LS & $1.2 \pm 0.4$ & $19.5 \pm 4.2$ & $1.7 \pm 0.5$ & $22.8 \pm 7.0$ & $2.1 \pm 0.8$ & $34.1 \pm 4.0$ \\
\hline & MS & $0.9 \pm 0.4$ & $0.8 \pm 0.1$ & $1.1 \pm 0.2$ & $1.0 \pm 0.2$ & $1.2 \pm 0.3$ & $1.1 \pm 0.3$ \\
\hline & $\mathrm{CS}$ & $3.2 \pm 1.4$ & $2.0 \pm 0.6$ & $7.3=1.4$ & $4.7 \pm 1.0$ & $3.9 \pm 1.3$ & $2.4 \pm 1.0$ \\
\hline & Total & $7.6 \pm 4.3$ & $1.3 \pm 0.6$ & $14.4 \pm 3.5$ & $2.5 \pm 0.8$ & $12.3 \pm 3.9$ & $2.4 \pm 0.9$ \\
\hline
\end{tabular}

Each of ${ }^{35} \mathrm{~S}-\mathrm{DSs}$ was given i.v. in a dose of $50 \mathrm{mg}(75 \mu \mathrm{Ci}) / \mathrm{kg}$. The animals were sacrificed 15 , 60 , and 180 min after the administration, and five subcellular (NC, nuclear; MT, mitochondrial; LS, lysosomal; MS, microsomal; CS, cytosol) fractions of the liver were fractionated by differential centrifugation. Values exhibit the mean and S.E.M. of four experiments. 
rapidly taken up by liver, whereas, after ${ }^{35} \mathrm{~S}-\mathrm{DS}-\mathrm{H}$, the uptake was slow. Even $24 \mathrm{hr}$ after ${ }^{35} \mathrm{~S}-\mathrm{DS}-\mathrm{M}$ or ${ }^{35} \mathrm{~S}-\mathrm{DS}-\mathrm{H}$ administration, about $20 \%$ of the radioactivity remained in liver, while levels in the blood were $100 \mathrm{dpm} / \mathrm{ml}$.

About half of the radioactivity of liver was found in the cytosol fraction 15-60 min after ${ }^{35} \mathrm{~S}-\mathrm{DS}$ administration. In this fraction, the values expressed as per cent of the radioactivity of liver progressively decreased with increases in the nuclear fractions. The subcellular distribution of the radioactivity was similar among all the ${ }^{35}$ S-DSs used.

The specific radioactivity was significantly higher in the lysosomal than in the other fractions. In the lysosomal fraction, the activity was 5-10 times higher than in the cytosol fraction. At this time, no acid phosphatase activity was found in the cytosol fraction.

Paper chromatograms of the subcellular fractions are shown in Fig. 1. In the lysosomal fraction $15 \mathrm{~min}$ after ${ }^{35} \mathrm{~S}-\mathrm{DS}-\mathrm{L}$ administration, two peaks of the radioactivity were found (Fig. 1-A). One of these peaks was confirmed to be inorganic ${ }^{35} \mathrm{~S}$-sulfate ( $\mathrm{Rf} 0.70-0.75$ ), and the other unchanged ${ }^{35} \mathrm{~S}-\mathrm{DS}-\mathrm{L}$ (Rf 0.90-0.95). From the lysosomal fraction $15 \mathrm{~min}$ after ${ }^{35} \mathrm{~S}-\mathrm{DS}-\mathrm{H}$ administration, another peak of the radioactivity was detected at $\mathrm{Rf} 0.10$ 0.20. This radioactive fraction was identified by subsequent paper electrophoresis, as mentioned below. Unchanged ${ }^{35} \mathrm{~S}-\mathrm{DS}-\mathrm{H}$ is not shown in this figure, because DSs with AMW of more than 10,000 and SC of $18 \%$ were previously removed by the formation of CPC-DS complex.

In the paper chromatogram of the microsomal fraction $1 \mathrm{hr}$ after ${ }^{35} \mathrm{~S}-\mathrm{DS}-\mathrm{H}$ administration, other radioactive peaks also were found at $\mathrm{Rf} 0.25-0.30$ and $\mathrm{Rf} 0.40$ (Fig. 1-B). These peaks are probably the fraction of "active" sulfate and sulfate-containing amino acids, for example tyrosine-O-sulfate. These peaks exhibited characteristics of metachromasie-negative and hinhydrinepositive and were identified by comparing Rf values in another paper chromatography for the analysis of amino acids and "active" sulfates with those of references.

In the paper electrophoretic pattern of the extract of the lysosomal fraction $1 \mathrm{hr}$ after ${ }^{35} \mathrm{~S}-\mathrm{DS}-\mathrm{M}$, only the unchanged form was found (Fig. 2). In ${ }^{35} \mathrm{~S}-\mathrm{DS}-\mathrm{H}$, the desulfated and its depolymerized forms were observed in the cytosol fraction $3 \mathrm{hr}$ after the administration (Fig. 3).

The distribution of ${ }^{35} \mathrm{~S}-\mathrm{DSs}$ and their radioactive metabolites in the cytosol fraction is summarized in Table 2. At 15 min after administration of ${ }^{35} \mathrm{~S}-\mathrm{DS}-\mathrm{L}$ or ${ }^{35} \mathrm{~S}-\mathrm{DS}-\mathrm{M}$, the radioactivity of the

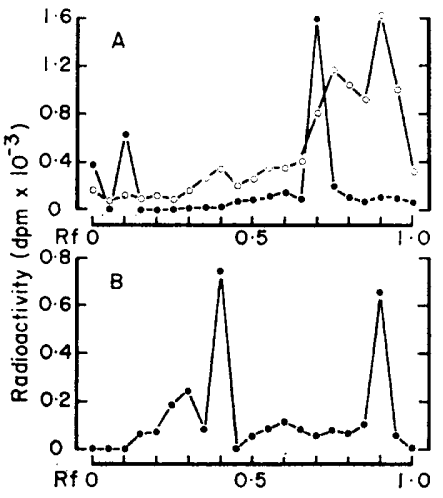

FIG. 1. Distribution of the radioactivity in paper chromatogram of the extracts of subcellular fractions of rat liver after i.v. administration of ${ }^{35} \mathrm{~S}-\mathrm{DS} 50 \mathrm{mg} / \mathrm{kg}$. The lysosomal fraction at $15 \mathrm{~min}(\mathrm{~A})$ and the microsomal fraction at $1 \mathrm{hr}$ (B) after administration of ${ }^{35}$ S-DS-L (O) or ${ }^{35} \mathrm{~S}-\mathrm{DS}-\mathrm{H}$ (O). ${ }^{35} \mathrm{~S}-\mathrm{DS}$ s with AMW of more than 10,000 and $\mathrm{SC}$ of $18 \%$ are not shown as such were removed by the CPC method. 


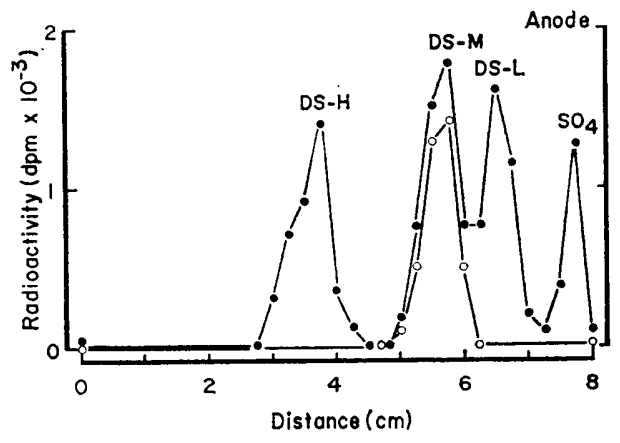

FIG. 2. Distribution of the radioactivity in paper electrophoretic pattern of the extract (C) of the liver lysosomal fraction at $1 \mathrm{hr}$ after ${ }^{35} \mathrm{~S}-\mathrm{DS}-\mathrm{M}$ administration. The radioactive references $(O), \mathrm{Na}_{2}{ }^{35} \mathrm{SO}_{4},{ }^{35} \mathrm{~S}-\mathrm{DS}-\mathrm{L},{ }^{35} \mathrm{~S}-\mathrm{DS}-\mathrm{M}$ and ${ }^{35} \mathrm{~S}-\mathrm{DS}-\mathrm{H}$, are shown in this figure. $\mathrm{SC}$ of these DSs is $18 \%$.

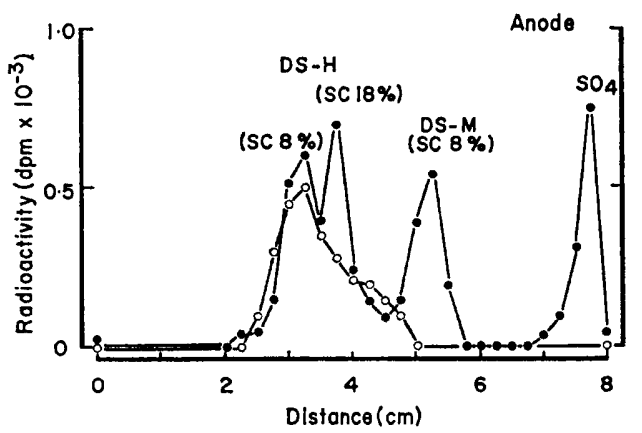

FIG. 3. Distribution of the radioactivity in paper electrophoretic pattern of the extract (C) of the liver cytosol fraction at $1 \mathrm{hr}$ after ${ }^{35} \mathrm{~S}-\mathrm{DS}-\mathrm{H}$ administration. The radioactive references (O), $\mathrm{Na}^{35}{ }_{2} \mathrm{SO}_{4},{ }^{35} \mathrm{~S}-\mathrm{DS}-\mathrm{M}$ and ${ }^{35} \mathrm{~S}-\mathrm{DS}-\mathrm{H}$ with $\mathrm{SC}$ of $8 \%$ (their desulfated form), and ${ }^{35}$ S-DS-H with SC of $18 \%$, are shown here.

unchanged forms was about half of that found in the cytosol fraction. The unchanged ${ }^{35}$ S-DS-H was only $5 \%$. All the radioactive metabolites we expected to find were detected from the cytosol fraction.

The highest specific radioactivity was found in the lysosomal fraction after ${ }^{35} \mathrm{~S}-\mathrm{DS}$ administration, in which most of the radioactivity was detected from the fraction of unchanged ${ }^{35}$ S-DSs. Thus, DSs may be partly transferred to the lysosomes during endocytosis. It has been shown that a part of lysosomal membranes is probably derived from plasma membranes during endocytosis $(9,10)$. Considering these findings, $\mathrm{Na}^{+}-\mathrm{K}^{+}-$ dependent ATPase activity, a marker enzyme of the membranes, was assayed in the lysosomal fraction after DS administration. When ${ }^{35} \mathrm{~S}-\mathrm{DS}-\mathrm{M}$ or ${ }^{35} \mathrm{~S}-\mathrm{DS}-\mathrm{H}$ was given i.v., the ATPase activity in the lysosomal fraction of liver was enhanced (Fig. 4). The ATPase in particular was enhanced even $24 \mathrm{hr}$ after DS-H administration. The enhancement of $\mathrm{Na}^{+}-\mathrm{K}^{+}-$ dependent ATPase activity corresponded with increases in the specific radioactivity in the lysosomal fraction. Accordingly, these results indicate that DS, especially with high AMW, can be transferred partly to liver lysosomes by endocytotic transport. 
TABLE 2. Distribution of ${ }^{35}$ S-DSs and their radioactive metabolites in liver cytosol fraction

\begin{tabular}{|c|c|c|c|c|c|c|}
\hline \multirow{2}{*}{\multicolumn{2}{|c|}{ Treatment Time }} & \multicolumn{5}{|c|}{ Per cent of the radioactivity in the cytosol fraction" } \\
\hline & & \multirow{2}{*}{$\frac{\text { Unchanged }}{53.2(4.8)}$} & \multirow{2}{*}{ Depolymerized } & \multirow{2}{*}{$\frac{\text { Desulfated }^{d}}{0}$} & \multirow{2}{*}{$\frac{\text { Inorganic }{ }^{35} \mathrm{~S}}{35.4(3.2)}$} & \multirow{2}{*}{$\frac{\text { Non-saccharide }}{11.3(1.0)}$} \\
\hline DS-I & $15 \mathrm{~min}$ & & & & & \\
\hline & $3 \mathrm{hr}$ & $18.9(0.2)$ & - & 0 & $9.8(0.1)$ & $71.3(0.7)$ \\
\hline \multirow{3}{*}{ DS-M } & $15 \mathrm{~min}$ & $39.7(4.4)$ & 0 & 0 & $4.0(0.4)$ & $56.2(6.5)$ \\
\hline & $3 \mathrm{hr}$ & $61.1(4.8)$ & $16.7(1.3)$ & 0 & 0 & $22.2(1.8)$ \\
\hline & $24 \mathrm{hr}$ & $22.4(1.2)$ & $35.3(1.9)$ & 0 & 0 & $42.3(2.3)$ \\
\hline \multirow{3}{*}{ DS-H } & $15 \mathrm{~min}$ & $4.1(0.1)$ & $4.6(0.1)$ & $54.7(1.8)$ & $26.6(0.9)$ & $10.1(0.3)$ \\
\hline & $3 \mathrm{hr}$ & $4.5(0.2)$ & $31.8(1.2)$ & $16.7(0.7)$ & $30.3(1.2)$ & $16.7(0.7)$ \\
\hline & $24 \mathrm{hr}$ & 0 & 0 & $19.7(1.1)$ & $23.0(1.3)$ & $57.3(3.2)$ \\
\hline
\end{tabular}

a, Rats were sacrificed $15 \mathrm{~min}, 3$ and $24 \mathrm{hr}$ after i.v. administration of ${ }^{35} \mathrm{~S}$-DS. The radioactivity was fractionated by the cetylpyridinium chloride method and the subsequent paper chromatography and electrophoresis. Each value indicates the mean of four experiments. The values in parenthesis show the means of those expressed as per cent of the radioactivity given. b, Unchanged ${ }^{35} \mathrm{~S}-\mathrm{DS}$, initial form. c, ${ }^{35} \mathrm{~S}-\mathrm{DS}$ depolymerized to that with AMW of less than 3000 and SC of $18 \%$. d, ${ }^{35}$ S-DS desulfated to that with SC of $8 \%$ or below and the initial AMW. e, ${ }^{35} \mathrm{~S}$ radioactivity incorporated into substances of non-saccharides.

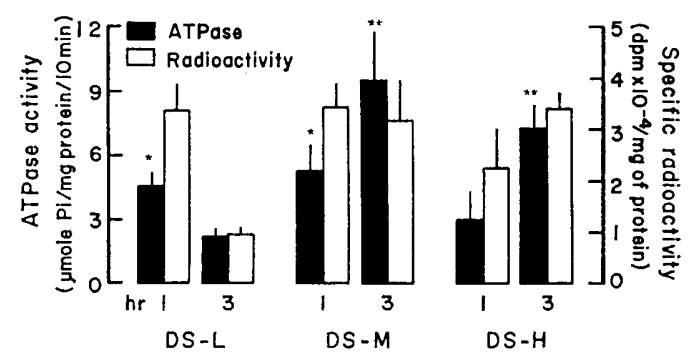

FIG. 4. Comparison of $\mathrm{Na}^{+}-\mathrm{K}$-dependent ATPase and the specific radioactivity of rat liver lysosomal fraction after i.v. administration of ${ }^{35} \mathrm{~S}-\mathrm{DS} 50 \mathrm{mg} / \mathrm{kg}$. The ATPase activity of the liver lysosomal fraction in non-treated rats was $2.84=0.97 \mu$ moles $\mathrm{Pi} / \mathrm{mg}$ of protein $/ 10 \mathrm{~min}$. Each column shows the mean of four experiments, and the vertical lines show S.D. Statistically different from the value of the nontreated group, ${ }^{*}, \mathrm{P}<0.05 ;{ }^{* *}, \mathrm{P}<0.01$.

\section{DISCUSSION}

Our findings suggest that DSs can indeed enter liver cells, despite a high AMW. The question then arises as to whether or not ${ }^{35} \mathrm{~S}$-DSs detectable in the subcellular fractions of liver may have derived from ${ }^{35} \mathrm{~S}-\mathrm{DS}$ s distributed to extracellular space and ${ }^{35} \mathrm{~S}-\mathrm{DSs}$ bound to the outer plasma membranes of liver cells. When the livers were perfused with $0.9 \%$ saline and subsequently with $0.25 \mathrm{M}$ sucrose after ${ }^{35} \mathrm{~S}-\mathrm{DS}$ administration, there was no radioactivity in the final perfusate. Thus, the former ${ }^{35} \mathrm{~S}-\mathrm{DS}$ s were apparently removed from the liver. The latter ${ }^{35} \mathrm{~S}-\mathrm{DSs}$, including those bound to extracellular matrix, are probably concentrated in the nuclear and microsomal fractions after subcellular fractionation of the liver. The 
subcellular distribution of the radioactivity changed with the passage of time, even within $3 \mathrm{hr}$ after the administration. In the general circulation, there are no enzymes such as aryl sulfatase and dextranase catabolizing DSs. Accordingly, it is reasonable that changes in the subcellular distribution do reveal to some degree the transport and catabolism of DSs in liver cells.

In preliminary experiments, when ${ }^{35} \mathrm{~S}-\mathrm{DSs}$ were added to $10 \%$ homogenates of the livers of non-treated rats in a final concentration of $0.125 \mathrm{mg} / \mathrm{ml}$, after subcellular fractionation, over $85 \%$ of the radioactivity added was recovered from the cytosol fraction. The remaining radioactivity was found to be mainly in the nuclear and mitochondrial fractions. Therefore, during subcellular fractionation, the binding of ${ }^{35} \mathrm{~S}-\mathrm{DSs}$ of the cytosol to subcellular particulates, such as lysosomes and microsomes, can be neglibible.

After intravenous administration of ${ }^{35} \mathrm{~S}-\mathrm{DS}-\mathrm{L}$ or ${ }^{35} \mathrm{~S}-\mathrm{DS}-\mathrm{M}$, about half of the radioactivity of liver was detected from the cytosol fraction as unchanged ${ }^{35} \mathrm{~S}-\mathrm{DS}$. Aronson and Davidson (11) showed that, when chondroitin sulfates labeled with ${ }^{3} \mathrm{H}$ and ${ }^{35} \mathrm{~S}$ were given i.v., about $60 \%$ of each of the radioactivities of liver was detected in the cytosol fraction. Thus, it appears that acid polysaccharides, such as chondroitin sulfates and DSs, can be transferred to cytosol across the plasma membranes of liver cells. If the lysosomes in which DS was remarkably concentrated had been labilized, DS would have diffused to the cytosol fraction simultaneously with lysosomal enzymes. Acid phosphatase activity, a marker enzyme of lysosomes, did not increase in the cytosol fraction. Accordingly, DSs with AMW of 200,000 or below are probably transferred to the cytosol by a transmembrane transport. Such may possibly be the result of an increased fragility of the plasma membrane, as induced by DSs.

Meijer and Willighagen (12) reported that, when dextran with high AMW was given to mice, many granules which they had termed "peribiliary bodies" were formed in liver cells. Similar findings have been shown by other investigators (13-15). DeDuve (16) showed that these granules can be collected from the lysosomal fraction by the method of subcellular fractionation, and after administration of ${ }^{14} \mathrm{C}$-sucrose, the granules may be formed by the invagination of the plasma membranes on which the sucrose adsorbed. In our present experiment, about $10 \%$ of the radioactivity and the highest specific radioactivity of liver were found in the lysosomal fraction after ${ }^{35} \mathrm{~S}-\mathrm{DS}$ administration. In particular, ${ }^{35} \mathrm{~S}-\mathrm{DS}-\mathrm{M}$ in this fraction was found to be in an unchanged form. These results indicate that DSs can enter liver cells during endocytosis, whereas there is a small quantity of DSs transferred by this system. We have already shown that, when ${ }^{35}$ S-DS with AMW of 200,000 (DS-H) was intraduodenally given to rats, $40 \%$ of the radioactivity taken up by intestinal mucosa was detected in the lysosomal fraction (3). Thus, the radioactivity of ${ }^{35} \mathrm{~S}-\mathrm{DS}$ s distributed to the lysosomal fraction of liver cells may disappear rapidly by the desulfation of ${ }^{35} \mathrm{~S}-\mathrm{DSs}$ and the subsequent diffusion of inorganic ${ }^{35} \mathrm{~S}$-sulfate ion across the lysosomal membranes to the cytosol, and by excretion into the bile. The former possibility is supported by the fact that, after ${ }^{35} \mathrm{~S}$-DS administration, inorganic ${ }^{35} \mathrm{~S}$-sulfate were found in both the lysosomal and cytosol fractions. Regarding the latter possibility, there is the evidence that, after i.v. 
administration of ${ }^{35} \mathrm{~S}-\mathrm{DSs}$, large amounts of the radioactivity and high acid phosphatase activity were detected in the bile (17).

Part of lysosomal and pinosomal membranes are probably derived from plasma membranes during endocytosis (10). $\mathrm{Na}^{+}-\mathrm{K}^{+}$-dependent ATPase activity of a lysosomal fraction is considered to be an index of endocytosis (9). Thus, the view for the endocytotic transport of DSs can be supported by the finding that DSs enhanced the activity of a marker enzyme of plasma membranes, $\mathrm{Na}^{+}-\mathrm{K}^{+}$-dependent ATPase, in the lysosomal fraction of liver. In addition, we found that increases in the ATPase activity of the lysosomal fraction of intestinal mucosa corresponded with the amounts of DSs distributed to the fraction (3).

Mechanisms involved in endocytotic and transmembrane transports of DSs require further study. However, we have determined that in vitro, DSs bind to the plasma membrane of liver and are accompanied by calcium ions (18). The binding may trigger the invagination of plasma membrane.

Thus, DSs can enter liver cells via transmembrane transport, and by endocytotic transport, in particular DSs with a high AMW. In liver cells, DSs are desulfated and depolymerized.

\section{REFERENCES}

1) Estes, J.W.: The kinetics of heparin. Ann. N. Y. Acad. Sci. 179, 187-204 (1971)

2) KaPlan, D. and MeYer, K.: The fate of injected mucopolysaccharides. J. clin. Invest. 41, 743-749 (1962)

3) Kagawa, K., Nishiyama, M. and Tomizawa, S.: Transport and metabolism of dextran sulfates and the effect of calcium. Biochem. Pharmacol. 27, 1931-1937 (1978)

4) DeDuve, C., Pressman, B.C., Gianetto, R.G., Wattiaux, R. and Appelmans, F.: Tissue fractionation studies. 6 . Intracellular distribution patterns of enzymes in rat liver tissue. Biochem. J. 60, 604-617 (1955)

5) Scort, J.E.: Aliphatic ammonium salts in the assay of acidic polysaccharides from tissues. Meth. biochem. Anal. 8, 145-197 (1960)

6) Ricketts, C.R., Walton, K.W. and Soddington, S.M.: Preparation of dextran ${ }^{35}$ Ssulfate and tracer experiments in the rabbit. Biochem. J. 58, 532-536 (1954)

7) Quigley, J.P. AND GotTerer, G.S.: Distribution of $\left(\mathrm{Na}^{+}-\mathrm{K}^{+}\right)$-stimulated ATPase activity in rat intestinal mucosa. Biochim. Biophys. Acta 173, 456-468 (1969)

8) Lowry, O.H., Rosebrough, N.J., Farr, A.L. and Randall, R.J.: Protein measurement with the Folin phenol reagent. J. biol. Chem. 193, 265-275 (1951)

9) DunCan, C.J.: Properties and stabilization of the lysosomal membrane. Nature 210, 1229_. $1230(1966)$

10) WerB, Z. AND CoHN, Z.A.: Plasma membrane synthesis in the macrophage following phagocytosis of polystyrene particle. J. biol. Chem. 247, 2439-2446 (1972)

11) Aronson, N.N. and Davidson, E.A.: Catabolism of mucopolysaccharides by rat liver lysosomes in vivo. J. biol. Chem. 243, 4494-4499 (1968)

12) Mfijer, A.E.F.H. And Willighagen, R.G.J.: The activity of glucose 6-phosphatase, adenosine triphosphatase, succinate dehydrogenase, and acid phosphatase after dextran or polyvinylpyrolidone uptake by liver in vivo. Biochem. Pharmacol. 12, 973-980 (1963)

13) DeMan, J.C.H., Daems, W.T., Willighagen, R.G.J. and VanRiussel, T.G.: Electrondense bodies in liver tissue of the mouse in relation to the activity of acid phosphatase. J. Ultrastruct. Res. 4, 43-57 (1960)

14) Casley-Smith, J.R.: Endothelial permeability. II. The passage of particles through the lymphatic endothelium of normal and injured ears. Brit. J. exp. Med. 46, 35-49 (1965)

15) DeDuve, C. and Wattiaux, R.: Functions of lysosomes. A. Rev. Physiol. 28, 435-492 (1966) 
16) DeDuve, C.: The lysosome conception. Lysosomes, p. 1-31, Ciba Found. Symp. (1963)

17) Kagawa, K. And Tomizawa, S.: Studies of the metabolism of dextran sulfates. 5) Effects of dextran sulfates on rat liver lysosomes and influence of calcium. Japan. J. Pharmacol. 22, Supp. 61P (1972)

18) Kagawa, K. And Tomizawa, S.: Activation of $\mathrm{Ca}^{2+}$-ATPase of liver plasma membrane by dextran sulfates. Biochem. biophys. Res. Commun. 86, 704-709 (1979) 